\title{
Reflexos da Ideia Aristotélica de Bem no Livro dos Castigos del Rey Sancho IV
}

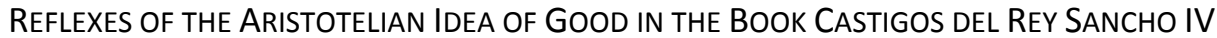

\author{
Adailson José Rui* \\ adailson.rui@unifal-mg.edu.br \\ Paulo César de Oliveira** \\ deoliveirapc@yahoo.com.br
}

ResUmo: O livro dos Castigos del Rey Sancho IV foi concluído em Castela por volta de 1293. Trata-se de um espelho de príncipe, no qual os autores usaram o monólogo como instrumento de persuasão. O pai, no caso Sancho IV, rei de Leão e Castela de 1284 a 1295 ensina ao filho, o futuro Fernando IV 1295-1312 a maneira como deverá se comportar diante das mais diferentes situações, sempre tendo como propósito a condução de si, e de seus súditos em direção ao bem maior. Fazendo uso de exemplos, o pai apresenta ao filho o caminho a ser trilhado. Por meio dessa estratégia, os autores da obra adéquam o pensamento de Aristóteles de forma a sustentar a função do príncipe como guia de seus súditos em direção a Deus, função a ser desempenhada pelo monarca cristão. É nessa perspectiva que será apresentada a ideia do "Bem" definida por Aristóteles na obra Ética a Nicómaco, como suporte utilizado pelos autores do livro Castigos del Rey Sancho IV, para definir e apresentar as funções do Príncipe Cristão.

PALAVRAS CHAVE: Aristóteles, Sancho IV, Livro dos Castigos.

ABSTRACT: The Book of Castigos del Rey Sancho IV was completed in Castile around 1293. It is a prince mirror, in which the authors used the monologue as an instrument of persuasion. The father in the case Sancho IV, king of Castile and Leon 1284-1295 teach the son, the future Ferdinand IV (1295-1312) the way he should behave on the most different situations, always with the purpose to conduct themselves, and his subjects towards the greater good. Making use of examples, the father shows his son the way to go. Through this strategy, the authors of the work fit the thought of Aristotle in order to sustain the prince's role as guide his subjects toward God, role to be played by the Christian monarch. It is in this perspective that will be presented the idea of the "Good" defined by Aristotle in the Nicomachean Ethics, as a support used by the authors of the book Castigos del Rey Sancho IV, to define and present the functions of the Christian Prince.

KEY WORDS: Aristotle, Sancho IV, Book of "Castigos"

[...] assim, como nos Jogos Olímpicos, não são os mais belos e os mais fortes que conquistam a coroa, mas os que competem (pois é dentre estes que hão de surgir os vencedores), também as coisas nobres e boas da vida só são alcançadas pelos que agem retamente. (EN I, 1099a, p. 29) ${ }^{1}$.

\footnotetext{
${ }^{*}$ Doutorado em História pela Faculdade de Ciências e Letras, UNESP, campus de Assis (2003). Professor adjunto da Universidade Federal de Alfenas, UNIFAI-MG e Professor Permanente do Programa de Mestrado Profissional em História Ibérica da mesma Universidade.

** Doutorado em Filosofia pela Pontificia Università San Tommaso di Roma, Itália. Professor de Filosofia na Universidade Federal de Alfenas, UNIFAL-MG e Professor permanente do Programa de Mestrado Profissional em História Ibérica da mesma Universidade.

${ }^{1}$ ARISTÓTELES, Ética a Nicômaco. Tradução de Pietro Nasseti. São Paulo: Martin Claret, 2003. Ao longo do artigo as referências a essa obra serão feitas por meio da sigla "EN".
}

Hist. R., Goiânia, v. 21, n. 2, p. 180-197, maio/ago. 2016

Recebido em 22 de fevereiro de 2016 Aprovado em 08 de maio de 2016 


\section{O Livro dos Castigos de Sancho IV}

Em 1292, concluía-se na corte castelhana uma obra que ficaria conhecida com o título Castigos e documentos, cuja autoria foi atribuída a Sancho IV, rei de Castela e Leão de 1284 a 1295. O título Castigos e documentos foi a ela atribuída pela tradição editorial moderna que, segundo o filólogo argentino Hugo Oscar Bizzarri, procurou dar um nome mais ou menos homogênea a essa narrativa, em função da versão primitiva da mesma não conservar denominação. Dela, são conhecidos sete manuscritos e algumas edições publicadas. Os manuscritos são: A: 6559; B: 6603; Ms 3995 e Ms. 1970/40 conservados na Biblioteca Nacional de Madrid; E: Z. III. 4 conservado na Biblioteca de San Lorenzo de el Escorial; Ms 17/6/3 conservado na Biblioteca Particular Bartolomé March Cerví e, um manuscrito fragmentado conservado no Seminário de San Jerônimo, em Burgos. Outro manuscrito existiu no Seminário Conciliar de Siguënza até a guerra civil espanhola quando foi destruído. Entre as edições publicadas, podemos citar as de Pascual de Gayangos de 1860, a de Agapito Rey de 1952 e, mais recentemente, a de Juana Hidalgo Ogáyar e a de Hugo O. Bizzarri de 2001.

Neste estudo, utilizamos a edição de Pascual de Gayangos, editada em Madrid em 1952 pela Biblioteca de Autores Españoles e a de Hugo O. Bizzarri. A primeira possui como base o manuscrito 6559 da Biblioteca Nacional de Madrid, considerado na época da elaboração da edição como sendo o mais completo. Porém, nem por isso o mais fiel ao texto primitivo, pois, segundo Foulché-Delbosc (1906), o manuscrito 6559 foi contaminado pelos comentários de Frei Juan Garcia de Castrojeriz ao Regimento de Príncipes de Egidio Romano. Hugo O. Bizzarri considera essa crítica como válida. A edição preparada por ele possui como base o manuscrito [E], que segundo esse mesmo estudioso, foi confrontado em primeira instância com o manuscrito $[A]$ e em segunda com os manuscritos $[C$ e $B]$.

Outro aspecto, motivo de crítica, porém não especificamente da edição de Gayangos, mas sim colocada a todas as edições, é o nome Castigos e documentos atribuído a elas. Esse nome não foi bem aceito pelos estudiosos da obra. Para Manuel Cacho Blecua, por exemplo, a obra deveria ter como nome Castigos et consejos ou algo semelhante. Tendo como referência a edição de Gayangos, podemos verificar e justificar o posicionamento de Cacho Blecua, pois sobre o termo "castigo" o(s) autor(es) do Libro de los Castigos del Rey Don Sacho IV afirma(m): 
quiere tanto decir como apercibimiento de conoscer las cosas et non errar. Essa afirmação é reforçada na sequência seguinte: Et por cuanto á las veces acaesce que por los homes nos ser aconsejados é apercebidos, caen en muchos errores é menguas é vergueñas... (GAYANGOS, 1952, p 88). Tendo como referência a edição preparada por Bizzarri podemos entender castigos como ensinamentos a serem observados e seguidos. São "lições" que possuem como objetivo a transmissão de uma conduta.

No entanto, o mesmo não acontece com o termo "documentos", esse não é definido. 0 estudo da obra permite entender documentos como sendo os exemplos utilizados pelos autores para ilustrar as lições que desejam transmitir. Já o termo consejos, defendido por Cacho Blecua, é pertinente em função dos objetivos da obra, conforme apresentado no prólogo da mesma, no qual fica expresso que Sancho IV (1284-1295) e seus auxiliares (científicos sábios) a elaboraram como sendo um "manual" didático que deveria servir tanto a seu filho, o futuro Fernando IV, rei de Castela de 1295 a 1312, como àqueles que desejassem estar no bom caminho, a serviço de Deus.

Hugo Oscar Bizzarri resolveu a questão do título atribuindo a obra a denominação "Castigos del rey don Sancho IV". Independente da nomenclatura a obra referida foi elaborada para ser um instrumento que possibilitasse a percepção do bem, a percepção das boas coisas num mundo em que, de acordo com o pensamento religioso dominante, as tentações, os pecados e as maldades, de maneira geral, eram abundantes. Nas palavras dos autores:

Et porque los trabajos é tentaciones, pecados é engaños é males deste mundo son tales, é tales los sotilezas de los homes con que participamos, que mas pugnam de dar consejos de mala vivienda que de buena, habemos de buscar carrera derecha é verdadera que es Dios Nuestro Señor é los sus buenos dichos é castigos por naturalmente obrando, por ellos seremos puestos con los santos en la gloria celestial, do son todos los sus amados.

...poniendo mis fechos é mi entendimiento en aquel soberano altisimo Rey, muy poderos facedor de todas las cosas, sin la gracia del cual ninguna se puede facer, et catando que todo home es obligado de castigar, regir é administrar sus fijos, é dalles costumbres é regimiento de buenos castigos é dotrinas en que naturalmente pueden vivir é conocer á Dios é a si mesmos, é dar enjiemplo de bien vivir á los otros, é que esto pertenesce mayormente á los reyes é principes que han de gobernar reinos é gentes; con la gracia de Dios ordené é fice este libro para mi fijo, é dende para todos aquellos que del algun bien quisieren tomar é aprender...(CASTIGOS,2001,p.73). 
Como integrantes do pensamento cristão, os autores apresentaram no livro dos Castigos aquilo que consideravam como a conduta ideal, marcada pela justiça e pela integridade à verdade cristã. Para tanto, construíram a obra como uma guia que, segundo eles, o príncipe deveria seguir, objetivando a realização de sua missão. Estruturaram a obra como um monólogo no qual o pai, Sancho IV expõem ao filho, o futuro Fernando IV, a conduta a ser seguida. Fizeram uso de exemplos para reforçar e sustentar os ensinamentos transmitidos. Porém, o que utilizaram como sustentação para a construção de tal "guia"? No que consiste essa "guia"? A busca de respostas, para essas questões fizeram-nos perceber nos Castigos a presença do pensamento de Aristóteles, especificamente naquilo que se refere á temática do bem.

\section{A ideia do bem em Aristóteles}

No decorrer do século XIII, a presença do pensamento aristotélico já fazia parte da cultura cristã ocidental. Na Península Ibérica, tal pensamento já era conhecido anteriormente a esse século, em virtude dos trabalhos desenvolvidos na Escola de Tradutores de Toledo, onde sábios das três culturas (judeus, cristãos e muçulmanos) trabalhavam juntos, inicialmente traduzindo obras clássicas e posteriormente produzindo novos conhecimentos a partir do material traduzido ${ }^{2}$.

De Aristóteles é significativo, no caso específico do livro dos Castigos, a utilização da idéia do "Bem" e da forma como ele faz para apresentá-la, visto que para defini-la oferece uma série de esclarecimentos que nos levam a compreender que o bem é a felicidade absoluta.

Aristóteles identifica três formas de vida, a vida em busca do prazer, a vida política e a vida contemplativa (Cf. EN I 1096a). Há ainda outra forma que é a vida em busca da riqueza (Cf. EN I 1096a). Após constatar que há várias acepções do bem, Aristóteles passa a buscar o bem universal. O estagirita inicialmente acha isso um tanto penoso uma vez que fora Platão quem introduziu a doutrina das formas. A doutrina platônica do bem por certo é rejeitada. Diz Aristóteles: "O bem, portanto, não é uma generalidade correspondente a uma forma única" (Cf.

\footnotetext{
${ }^{2}$ No século XII surgiu, em Toledo, a primeira escola espanhola de tradutores do árabe para o latim. Essa escola foi fundada por D. Raimundo, monge beneditino nascido em Agen, no sudoeste da França, que foi arcebispo de Toledo de 1126 a 1151. Convencido da importância da obra dos filósofos árabes para a compreensão de Aristóteles, ele decidiu traduzir suas obras para o latim.
} 
EN I 1096a - 1097a). Este bem universal, ainda que possa existir, não é alcançado pelo homem como bem. Eis o que afirma Aristóteles:

Acontece o mesmo em relação à forma do bem; ainda que haja um bem único que seja um predicado universal dos bens, ou capaz de existir separada e independentemente, tal bem não poderia obviamente ser praticado ou atingido pelo homem, e agora estamos procurando algo atingível. Talvez alguém possa pensar que vale a pena ter conhecimento deste bem, com vistas aos bens atingíveis e praticáveis; com efeito, usando-o como uma espécie de protótipo, conheceremos melhor os bens que são bons para nós e, conhecendo-os, poderemos atingi-los (EN I 1097a).

Analisando os Castigos percebemos a relação entre a estrutura da obra com os passos de Aristóteles para expor a ideia do bem. Com o objetivo de esclarecer como esse processo acontece faremos, em uma primeira etapa, algumas considerações sobre como o bem é entendido por Aristóteles, na obra Ética a Nicômaco e na sequência apresentaremos como a idéia do bem é expressa nos Castigos. Para tanto, partimos dos dizeres que dão inicio ao primeiro livro da Ética a Nicômaco: "Admite-se geralmente que toda arte e toda investigação, assim como toda ação e toda escolha, têm em mira um bem qualquer; e por isso foi dito, com muito acerto, que o bem é aquilo a que todas as coisas tendem. " (EN I, 1094 a, p. 17).

A ideia de finalidade apresentada nesses dizeres estará sempre presente no que diz respeito à definição daquilo que para Aristóteles será entendido como sendo o bem. Na perspectiva aristotélica, arte, investigação, ação e escolha visam a algum bem. O bem é aquilo a que todas as coisas tendem, ou seja, a sua finalidade, a sua razão de ser. Desse modo, pode-se inferir que há tantos bens quantos sejam os fins existentes. Aristóteles apresenta exemplos retirados da medicina e da construção naval. Isto é, o bem da medicina é a saúde e o bem da construção naval é o navio.

Dentre os fins, há atividades e também os produtos derivados delas. A relação de dependência que se estabelece entre os fins forma uma espécie de hierarquia na qual alguns fins são buscados apenas como meios de se alcançar outros fins mais elevados. É o caso da selaria e das ações militares, que possuem seus próprios fins particulares; no entanto, se unem junto a outras artes para compor uma nova arte com fim próprio mais elevado: a estratégia. 
O bem do homem é realizar a sua função e deve ser algo que lhe é próprio. Disso exclui-se sua vida de nutrição e crescimento porque é algo que também está presente nas plantas. Também se exclui a vida de percepções porque esta é comum aos animais. Portanto, resta ao homem uma função que não está presente nas plantas e tampouco nos animais; esta função é exercer sua atividade racional. O exercício desta atividade é, pois, o bem próprio do homem.

Entretanto, Aristóteles afirma que há um fim que é perseguido por ele mesmo: o sumo bem. Trata-se de um bem absoluto e incondicional e que deve ser buscado por si mesmo. Ele representa o ponto de chegada deste encadeamento de fins. No homem, o conceito de sumo bem é idêntico ao conceito de felicidade. Esta é procurada sempre por si mesma e não como meio para se alcançar outras coisas.

A felicidade é algo absoluto e auto-suficiente; é a finalidade última de qualquer ação humana. Desse modo, o bem se identifica com a felicidade. Ela é o mais alto de todos os bens que se pode alcançar pela ação. Mas o homem somente atinge a felicidade se realizar com excelência a função que Ihe é própria. Para isso, ele precisa exercer sua atividade racional em consonância com a virtude. Além disso, se houverem várias virtudes, ele deve exercer tal atividade em conformidade com a melhor e mais perfeita. Além disso, o homem deve sentir prazer em praticar as ações virtuosas. Desse modo, a felicidade é uma atividade conforme à virtude perfeita.

Além desse aspecto, podemos destacar também, a ausência de uma tendência para o mal. Nada seguiria esse propósito, isto é nada teria como meta atingir o mal; sempre o almejado é o bem, qualquer que seja ele. Dessa maneira, o bem é entendido como sendo o fim último a ser alcançado.

Porém, no mesmo livro ele esclarece que o bem não é único, pois, o ser não é único; existem muitos seres, daí, existirem muitos fins, muitos bens. Exemplifica isso da seguinte forma: "na medicina é a saúde, na estratégia a vitória, na arquitetura uma casa". Tudo, independente do que seja, segue um propósito. Nessa perspectiva, o bem é a finalidade. É com base nela que os homens realizam todas as suas ações. No entanto, embora existam vários 
bens, segundo ele só há um fim absoluto e, por absoluto entende aquilo que merece ser buscado por si mesmo. A esse respeito Aristóteles expõe: "chamamos de absoluto $e$ incondicional aquilo que é sempre desejável em si mesmo e nunca no interesse de outra coisa" (EN I, 1096 b, p. 25). Por bem absoluto considera o que é auto-suficiente e, entende essa condição "como sendo aquilo que, em si mesmo, torna a vida desejável e carente de nada. " A felicidade encontra-se nessa categoria, pois, ela é sempre procurada em função dela mesma e

nunca com vistas em outra coisa, ao passo que à honra, ao prazer, à razão e a todas as virtudes nós de fato escolhemos por si mesmas (pois, ainda que nada resultasse daí, continuaríamos a escolher cada um deles); mas também os escolhemos no interesse da felicidade, pensando que a posse delas nos tornará felizes. A felicidade, todavia, ninguém a escolhe tendo em vista alguns destes, nem em geral, qualquer coisa que não seja ela própria (EN I, 1097b, p.26).

Dessa maneira afirma que "a felicidade é, portanto, algo absoluto e auto-suficiente, sendo também a finalidade da ação (EN I, 1097b, p.26). É na felicidade que o homem encontra o Bem supremo. Porém, nem sempre os homens têm ações positivas. O que determinará se ele caminha ou não para o bem é o fato de desempenhar ações que o conduza para a não felicidade ou para a plena felicidade, esta compreendida como sendo a atividade racional, característica própria do homem, pois, é essa capacidade que o distingue dos demais seres. Nas palavras de Aristóteles:

[e afirmamos ser a função do homem uma certa espécie de vida, e esta vida uma atividade ou ações da alma que implicam um princípio racional; e acrescentamos que a função de um bom homem é uma boa e nobre realização das mesmas; e se qualquer ação é bem realizada quando está de acordo com a excelência que lhe é própria, se realmente assim é], o bem do homem nos aparece como uma atividade da alma em consonância com a virtude, e, se há mais de uma virtude, com a melhor e mais completa (EN I, 1098a, p.27).

As nobres realizações são apresentadas como ações da alma que possibilitam o prazer. No entanto, o prazer é um estado da alma que se manifesta de forma específica em cada homem, isso ocorre de acordo com aquilo que ele ama.

Aristóteles, que defendeu um lugar para o prazer na felicidade, mesmo dando a entender que poderia ser o bem supremo, define, no livro X da Ética a Nicômaco, o que é o prazer e argumenta contra Eudoxo que afirma ser o prazer o Bem. Para o Estagirita, o prazer, 
como a visão, é completo em cada momento de sua existência. Em outras palavras, não pode ser um movimento, isto é, um processo de transição.

Isso se justifica porque todo movimento ocorre no tempo, tem um fim e se torna completo uma vez alcançado o fim. Cada parte do movimento é incompleta e diferente em forma uma da outra e do todo. Ao contrário, o prazer é perfeito (acabado, completo); é telos (fim) em cada movimento. Se fosse um movimento, uma transição, portanto, um preenchimento, nós não sentiríamos prazer até que alcançássemos o estado ao qual nos conduz o prazer. Porém, o prazer é algo completo e satisfatório em todo momento, assim como a atividade de perceber e de pensar.

Em suma, o prazer é algo perfeito, completo e próprio de nosso estado natural. Além disso, o prazer aperfeiçoa toda atividade prazerosa, ou seja, a visão, por exemplo, quando se encontra saudável e tem como objeto algo distintamente visível, a atividade de ver, necessariamente, é mais prazerosa e o mesmo é verdadeiro para qualquer outra atividade, assim como a do pensamento. O prazer completa a atividade, intensifica-a, torna-a mais prazerosa. Há de se esclarecer que o prazer não é condição precedente para que ocorra a boa atividade, ou para que bem ocorra a atividade; mas apenas para que ocorra melhor; na verdade, é o coroamento da boa atividade. A atividade já é por si só desejável, como a de perceber e a de pensar, o prazer a torna mais desejável. Por um lado, o prazer não surge sem a atividade, por outro, a atividade é incompleta sem prazer. Em outras palavras, nós fazemos melhor as coisas se sentimos prazer em fazê-las. E quanto menos sentimos prazer em fazer o que estamos fazendo, mais tendemos a fazer outras coisas, como as pessoas que comem mais doces no teatro quanto pior for a atuação dos atores, por exemplo.

Conforme Aristóteles: "para cada homem é agradável aquilo que ele ama: não só um cavalo ao amigo de cavalos e um espetáculo ao amador de espetáculos, mas também os atos justos ao amante da justiça e, em geral, os atos virtuosos aos amantes da virtude" (EN I, 1099a, p.29). No entanto, Aristóteles faz o seguinte esclarecimento:

na maioria dos homens os prazeres estão em conflito uns com os outros porque não são aprazíveis por natureza, mas os amantes do que é nobre se comprazem em coisas que têm aquela qualidade; tal é o caso dos atos 
virtuosos, que não apenas são aprazíveis a esses homens, mas em si mesmos e por sua própria natureza. Em conseqüência, a vida deles não necessita do prazer como uma espécie de encanto adventício, mas possui o prazer em si mesma (EN I, 1099a, p.30).

Os amantes do que é nobre atingem ao bem maior e, em virtude disso são felizes e lembrados, pois, "nenhuma função humana desfruta de tanta permanência como as atividades virtuosas..."(EN I, 1099a, p.30). A prática das virtudes faz com que o homem seja sempre feliz, pois, a ação virtuosa é parte da vida dele. Essa forma de viver fará com que ele suporte todas as "vicissitudes da vida com a maior nobreza e decoro" (EN I, 1100a, p.32) fazendo com que ele realmente seja um homem bom; um homem que suporte com dignidade todas as contingências da vida sempre tirando o maior proveito das circunstâncias (EN I, 1101a, p.34).

Porém, existem aqueles que, de alguma maneira estão distantes da vida virtuosa e, por isso, estão distantes do bem supremo. Como forma de impedir a perpetuação dessa situação deve-se agir fazendo uso da política, pois, o sumo bem é o objeto dela (EN I, 1094a, p.17). Nas palavras de Aristóteles:

Ninguém duvida de que o seu estudo [do sumo bem] pertence à arte mais prestigiosa e que mais verdadeiramente se pode chamar a arte mestra. Ora, a política mostra ser dessa natureza, pois é ela que determina quais as ciências que devem ser estudadas num Estado, quais são as que cada cidadão deve aprender, e até que ponto; e vemos que até as faculdades tidas em maior apreço, como a estratégia, a economia e a retórica, estão sujeitas a ela. Ora, como a política utiliza as demais ciências e, por outro lado legisla sobre o que devemos e o que não devemos fazer, a finalidade dessa ciência deve abranger as das outras, de modo que essa finalidade será o bem humano. Com efeito, ainda que tal fim seja o mesmo tanto para o individuo como para o Estado, o deste último parece ser algo maior e mais completo, quer a atingir, quer a preservar. Embora valha bem a pena atingir esse fim para um indivíduo só, é mais belo e mais divino alcançá-lo para uma nação ou para as cidades-Estados (EN I, 1094b p.18).

Portanto, por meio da atuação da Política, Aristóteles nos apresenta a forma como o bem pode ser alcançado, visto que a meta da Política é "fazer com que os cidadãos sejam bons e capazes de nobres ações (EN I, 1099a, p.30). Seguindo esse pensamento, a Política é apresentada como a responsável por fazer com que tanto o homem como o Estado atinjam o bem supremo. 
A finalidade do Estado é o concurso do "bem-viver", isto é, da felicidade do homem, que consiste na atualização de todas as potencialidades da sua natureza. Em outras palavras, o fim do Estado é promover a vida segundo a virtude, cujo prêmio é a bem-aventurança. Ora, as virtudes dianoéticas (intelectuais) estão acima das virtudes éticas, e, de certa forma, as comandam. Dentre as virtudes dianoéticas, a mais sublime é a virtude da sapiência (sophia) ou o hábito da contemplação (theorein), que consiste: tanto na intuição dos primeiros princípios (nous), como na emanação deles das ciências teoréticas (epistéme), dentre as quais a filosofia primeira é a mais excelente (Cf. EN 1,13,1103 a 3-11).

O ápice da contemplação, que por si já alcança o vértice da natureza humana, consiste na contemplação das coisas excelsas e divinas. Ora, a contemplação (theorein) e a ciência que deriva dela, metafísica (metá physiká), não é algo que se oponha de forma excludente à vida ativa da pólis. Ao contrário, como sem a visão nada podemos fazer, embora ela mesma não esteja ordenada a nenhuma ação, assim as ciências contemplativas (como a teologia ou filosofia primeira), constituem o critério de referência para a vida prática. Portanto, se a finalidade do Estado é promover a virtude, e a maior de todas elas são a sapiência, já que sem a sua aquisição nenhuma das outras virtudes chega à perfeição do estado de virtude, então, o Estado deve patrocinar, precipuamente, a aquisição desta virtude entre os homens.

\section{A idéia do bem e a organização dos Castigos de Sancho IV}

No século XIII, seguindo uma tendência que visava à elaboração de obras de cunho doutrinário - espelhos de príncipe - os autores do livro dos Castigos del Rey don Sancho IV além das referencias oferecidas pela Bíblia e pelos pais da Igreja também fizeram uso, no processo de elaboração do livro dos Castigos, tanto da idéia de bem definida por Aristóteles como da forma para se chegar a ela apresentada por esse pensador. No entanto, enquanto para Aristóteles atingir o bem era a meta e a tarefa da política, para os autores dos Castigos tal atuação permanecia nesse campo, porém deveria ser conduzida pelo príncipe, sendo este entendido como o vigário de Deus na terra. Para tanto, o príncipe deveria conhecer o bem já que, Deus "es infinida bondat, por tal todo lo que El faze es bueno e mal non puede auer començamiento nin 
fundamiento en El" (BIZZARRI, H. 2001, p. 71). Além de conhecer o bem, o príncipe deve aprender o caminho para chegar até ele.

Tal aprendizado poderia ser alcançado por meio dos ensinamentos contidos nos Castigos, obra constituída por cinqüenta capítulos. Neles encontram-se os ensinamentos que devem ser apreendidos e vivenciados pelo príncipe, pois, ao mesmo tempo que é o vigário de Deus no reino é também ele o espelho no qual os súditos devem ver e reconhecer a prática de conduta advinda de atuações virtuosas e ver no príncipe o exemplo de educador a ser seguido pois, embora todos os homens sejam obrigados a ensinar, reger e administrar seus filhos e darIhes e deixar para eles costumes e regimentos de bons ensinamentos nos quais possam naturalmente conhecer a Deus e a si mesmos e dar exemplo de bem viver aos outros. (BIZZARRI, H. 2001, p. 73) para os príncipes essa obrigação é maior, pois, têm como função governar reinos e pessoas.

Seguindo esse pressuposto, o príncipe é apresentado como sendo o guia dos seus súditos em direção a salvação, conduzindo a si e aos seus súditos a Deus, o bem supremo. Essa forma de pensar o papel a ser desempenhado pelo príncipe vai ao encontro da maneira como Aristóteles apresenta o que entende por virtude. Segundo ele, há duas espécies de virtude, a intelectual e a moral. A intelectual deriva do ensino, devido a isso requer experiência e tempo; a moral "é adquirida em resultado do hábito, não surge em nós por natureza" (EN. p.27), portanto, trata-se de uma construção. Seguindo essa idéia, o príncipe tem como missão em primeiro lugar a sua "capacitação" para o bem.

É com o propósito de auxiliá-lo nesse campo que os autores dos Castigos organizaram a obra de forma a fazer com que aquele que a conheça entenda primeiramente que, acima de tudo, o bem existe e que, apesar da presença do mal, há um caminho possível para se alcançar o bem. Frente aos males o príncipe, se quiser pode estar preparado tanto para se defender como para vencê-lo. Para tanto, é necessário que tenha os seguintes atributos: temor e conhecimento de Deus; crença firme e verdadeira; que seja firme e forte de coração; que seja justo, humilde e casto. Terá esses atributos se seguir os ensinamentos oferecidos pela doutrina cristã que, se ele quiser, oferece a ele os meios para tê-los. Porém para que seja possível tanto a defesa frente ao mal como a vitória sobre ele é necessário conhecê-lo. Nesse sentido, os 
autores ofereceram ao príncipe, por um lado, conhecimento dos males provocados entre outros, pela desobediência, pela luxuria, pela inveja, pela injustiça, pela mentira e pela preguiça. Por outro, esclarecem o valor positivo proporcionado pela obediência, pela justiça, pela prática da verdade e pela castidade e virgindade.

Para apresentar os valores negativos e os positivos os autores fazem uso de exemplos extraídos da Bíblia, de maneira especial do livro do Eclesiástico e dos Provérbios, de vidas de fiéis e de infiéis ao cristianismo. Com base nesse repertório sustentaram os ensinamentos que o pai dá ao filho. Dessa maneira, os autores tinham como meta apresentar a "riqueza" do ser justo, do ser íntegro à verdade cristã. Para tanto, apresentam como o bom cristão deveria conduzir a sua vida, pois o conhecimento contribuiria para o não errar. Seguindo essa perspectiva apresentam Sancho IV assumindo a autoridade de pai, concedida a ele por Deus, cujo dever é aconselhar e ensinar para o filho a boa conduta tanto no campo espiritual (alma) como no material (carne). Conforme o livro dos Castigos:

Mio fijo mucho amado: tu eres mio fijo carnal é de la mi simiente fuiste tu fecho, é como quier que tu seas mi fijo, Deos criador é facedor de todas las cosas es padre Del alma, ca él la fizo de nada; pues conviene que le guardes bien aquello que es su fechura; ca asi como yo, que só tu padre, quiero que guardes bien aquello que es de mi fechura é es el alma de que es facedor. Por ende para mientes á los castigos que te yo agora daré é veras en ellos que non son tan solamente castigos para la tu carne, mas son castigos que te face el tu padre celestial para la tu alma, é yo te los enseño o por él; ca alli do él tobo por bien é ordenó que yo fuese tu padre, alli me hobo él dado poder que te castigase por él e por mi (GAYANGOS, 1952, p. 87).

$\mathrm{Na}$ conduta que deve ser transmitida pelo pai ao filho percebe-se a continuidade de certos aspectos do "modelo de educação" do príncipe criado, entre outros, por Cícero e Sêneca seguidores da teoria platônica, cujo objetivo final era chegar à política legítima e justa educando virtuosamente os governantes. No entanto, em virtude da expansão e do predomínio do pensamento cristão, nota-se que sobre o estrato elaborado pelos pensadores romanos surgiu algo novo: a incorporação dos valores da doutrina cristã. Verifica-se isso ao observar que enquanto o príncipe romano tinha na razão o seu centro de referência, o príncipe cristão deve ser preparado para tê-lo nos valores expressos pela religião. Por meio dela chega-se a Deus, o supremo Bem. Dentre os autores cristãos que propagaram essa perspectiva podemos citar o 
Papa Gregório Magno (590-604) e Isidoro de Sevilha (560-636). O papa Gregório Magno (590604) apoiado nas Sagradas Escrituras, e tendo por mestre Santo Agostinho, elaborou a teoria sobre as atribuições do poder (RIBEIRO, D.V, 1995 p 32-33). Para ele, “o poder é uma missão, um dever, não um privilégio, e deve ser exercido em benefício da coletividade". Portanto, guiando-o para o bem. No entanto, o poder, conforme Gregório Magno, também pode ser maléfico a medida que pode inspirar, entre outros males, a ambição, a soberba e a tirania.

As ideias formuladas e propagadas por Gregório Magno inspiraram Isidoro de Sevilha (560-636) a também alertar os futuros monarcas sobre os perigos que o poder gera. Para Isidoro "a realeza estava a serviço do povo cristão". Nessa perspectiva, o monarca possuía o poder e a missão de guiar de forma justa o povo cristão em direção a Salvação. Para tanto, o monarca deveria ser preparado dentro dos moldes da religião para bem guiar o seu povo. Será essa a perspectiva seguida pelos elaboradores do livro dos Castigos do Rei Sancho IV.

No final do século XIII os autores dos Castigos demonstram, por um lado, estar menos preocupados com os perigos que o poder pode causar e, por outro, revelam-se mais atentos com a valorização dos princípios cristãos e com a missão de guia e espelho que o príncipe deveria exercer. Nesta direção apresentam ao futuro rei os valores cristãos que devem sempre ser lembrados e praticados por ele. Dessa maneira, constroem e legitimam a memória histórica que desejam deixar registrada como referência a ser ou não ser seguida 3 .

A construção da memória histórica no livro dos Castigos é clara. É expressa, por exemplo, na valorização dos ensinamentos da doutrina cristã como sendo de fundamental importância na formação intelectual e moral do futuro rei. Embora seja reconhecido que o poder espiritual e o poder temporal têm a origem em Deus, fica claro o propósito de exaltação do poder espiritual.

O livro dos Castigos, portanto foi elaborado como sendo um instrumento que contém ensinamentos, que faziam com que o príncipe não viesse a se perder no caminho do mal, e sim

\footnotetext{
${ }^{3}$ Seguimos como definição de "construção da memória histórica" a apresentada por J. Angel Sesma Muños, para o qual é " el muestrario de ritos, ceremonias y acontecimientos que sucesivamente se incorporan al acervo cultural colectivo para servir de andamiaje al constante tejer y destejer de la interpretación del pasado, es consecuencia de la necesidad de entender los sucesivos presentes (SESMA MUÑOZ, 2004, p. 17). 
que tivesse um modelo, no qual pudesse se espelhar de maneira a conduzir a sua vida e a de seus súditos, de acordo com os preceitos de Deus. Evita-se o erro por conhecê-lo e consequentemente por saber os malefícios que ele proporciona. O conhecimento é valorizado, pois ele é considerado como o recurso necessário que propicia o bem viver, e nesse caso, o bem viver é estar com Deus. Contudo aqui o "conhecimento" deve ser entendido como sendo as verdades cristãs e nesse caso, apresentadas no Livro dos Castigos, cuja função é servir de guia ao príncipe no cumprimento de sua missão que é guiar os seus súditos no caminho do Bem. Para tanto, é condição necessária ser justo.

Visando possibilitar ao príncipe os meios para que seja ele um praticante da justiça, os autores do Livro dos Castigos elaboraram um conjunto de ensinamentos. Partem de duas falas atribuídas ao rei Salomão. A primeira "Amad justiçia vos que judgades la tierra" e a segunda "Derecho judgad a los fijos de los ome"(BIZZARRI, H. 2001 p.120). Segundo os autores do Livro dos Castigos os ensinamentos contidos nas duas frases dizem muito para os reis e príncipes, pois eles "tienen logar de Dios en la tierra que han de fazer e mantener justiçia e derecho amar justiçia" (BIZZARRI, H. 2001, p. 120).

Definem como justiça o ato de "dar a cada vno su derecho: dar al bueno galardón del bien e dar al malo galardón del mal". Aquilo que faz seguindo retamente a justiça quem a faz é ela e não o príncipe. Como exemplo apresenta a seguinte afirmação: "Si tu por justiçia derecha mandas al omne matar, non la fazes $t u$, ca el derecho la faze pues que derecho es (BIZZARRI, $\mathrm{H}$. 2001, p. 120).

Porém, para se fazer justiça é necessário que se tenha alguns cuidados: o primeiro deles recomenda que não se deve fazê-la quando estiver com raiva pois, poderá forçar o direito e dessa maneira errará no julgamento. Como medida para se proteger desse possível erro recomendam: "Quando dieres juyzio de justiçia tira toda sanna de tu coraçon, e tem sobre tu cabeça la espada del themor de Dios" (BIZZARRI, H. 2001, p. 121).

Ter a consciência de que Deus está acima é fundamental, visto que Ele tem o conhecimento do todas as ações feitas pelo príncipe. Dele não há como fugir. Portanto, não há como o príncipe, caso tome alguma medida de forma injusta, considerá-la justa em virtude do 
poder que detém. Deus está acima e tudo sabe e com justiça julgará o príncipe. Portanto, cabe ao príncipe sempre fazer uso da justiça de maneira que não tenha dúvida quanto a medida a ser tomada. Quando não souber ou ficar em dúvida quanto ao como proceder, os autores do Livro dos Castigos apresentam a ele três conselhos:

El primero, pide merçed a Dios, cuyo logar tienes, que te deve escojer lo mejor e te meta em la Carrera pordo lo tu puedes fallar. La segunda, cuenta e trabaja em El tu coraçón sobre ello. Lo terçero, demanda consejo a omnes Buenos e entendidos e sábios que te sepan consejar sobre tal cosa (BIZZARRI, H. 2001, p. 121).

Fazer a justiça mediante o conselho dos sábios é a melhor maneira do príncipe fazer a justiça sem temer, que recaia sobre ele alguma punição em virtude de um possível erro, pois a culpa do erro seria dos conselheiros dele. Desta maneira o príncipe/rei preserva a sua condição de liderança de forma plena, sem erros. A parte dessas observações que visam preservar o príncipe frente a possíveis injustiças, os autores do Livro dos Castigos enfatizam o como o correto uso da justiça pelo príncipe o valoriza diante de seus súditos que nele reconhecem a paz no reino, portanto, guiá-lo e mantê-lo no Bem.

\section{Conclusão}

Se, para Aristóteles, a finalidade do Estado é promover a virtude, e a maior de todas é a sapiência, por meio da qual o homem tem as possibilidades de atingir a perfeição, para os autores do Livro dos Castigos é função do príncipe ser o modelo de boa conduta a ser seguida pelos seus súditos e o responsável em proporcionar a eles os meios de se alcançar o bem supremo, sendo esse entendido como a salvação da alma. Nessa direção, os autores enfatizaram o papel e a responsabilidade do príncipe quanto a ser aquele que cuida e apresenta o melhor caminho aos seus súditos, sendo o melhor caminho entendido como aquele que é regido pelos ensinamentos e normas da Igreja. A função do Príncipe, apresentada pelos autores do Livro dos Castigos, assim como a função do Estado apresentada por Aristóteles em Ética a Nicômaco, no caso do Bem, são semelhantes.

O papel a ser desempenhado pelo Estado, conforme Aristóteles apresenta é no Libro de los Castigos atribuído ao Príncipe. Porém, o Príncipe, pela sua condição de vigário de Deus também necessita seguir a conduta transmitida pela Igreja e expressa nos ensinamentos 
contidos no Libro de los Castigos, obra resultante do trabalho elaborado por religiosos que, nela reuniram saberes, cuja origem encontra-se na antiguidade pagã, porém cristianizados pelos pais da Igreja, com ensinamentos bíblicos e vidas de santos. Como exemplo, entre outros, destacamos aqueles que fizeram com que o rei Salomão passasse a ser conhecido como modelo de rei justo. Será por meio da prática da justiça que o Príncipe/rei conduzirá os seus súditos na caminhada em direção ao supremo Bem, a salvação.

Envolvidos pelo conhecimento de obras de Aristóteles que, por meio dos árabes chegavam ao Ocidente, de maneira especial na Península Ibérica, os autores do Libro de los Castigos produziram uma fusão dos conhecimentos: os já cristãos foram enfatizados e muitos dos não cristãos foram cristianizados, proporcionando a sustentação daquilo que propunham ao Príncipe como meio para atingir o Bem.

A posição dos cristãos se inspira, sobretudo, em Tomás de Aquino (1225-1274) e nos árabes, principalmente, Avicena e Averróis. Para os árabes quanto para Tomás de Aquino, há dois tipos de conhecimento: o conhecimento particular que é feito por meio dos sentimentos e o conhecimento universal que resulta de operações abstratas ou intelectivas. A passagem do conhecimento particular para o conhecimento intelectivo é feita pela atividade do entendimento "ativo" que abstrai do concreto o elemento universal.

Para Tomás, Avicena e Averróis, tal como para Aristóteles, não existem idéias inatas e a nossa mente é uma "tabula rasa" em que o nosso conhecimento é a percepção do sensível. A nossa mente não pode ter conhecimento direto de substâncias imateriais pois estas não estão ao alcance dos sentidos (nihil est in intelectum quod prius non fuerit in sensu). Embora não possamos conhecer Deus, sumo Bem, diretamente, podemos conhecê-Lo analogicamente, por meio dos objetos sensíveis que manifestam a sua existência.

Se para Aristóteles a verdadeira felicidade está na contemplação filosófica, para Tomás de Aquino e para os pensadores árabes a felicidade só pode ser encontrada em Deus, que é o Bem Supremo. É a razão que deve orientar o homem para o seu fim levando-o a procurar o bem e a evitar o mal. Há uma lei natural que indica ao homem os preceitos a seguir segundo os princípios da reta razão. Mas, tanto para cristãos como para os árabes, acima da lei natural, está 
a eterna que existe em Deus e que é a origem e a fonte da lei natural. Já Aristóteles, não ultrapassa os limites da phisis, fato que gerou a oposição sistemática de cristãos e dos pensadores árabes, isso ocorreu até que se dessem inicio aos estudos realizados pelos tradutores medievais que, pouco a pouco, foram encontrando nos textos do estagirita fundamentos que colaboraram no campo da fé e no pensamento político que passavam a desenvolver. Na Península Ibérica especialmente em Castela a elaboração do Libro de los Castigos del Rey Don Sancho IV expressa essa prática.

\section{FONTES}

ARISTÓTELES, Ética a Nicômaco. Tradução de Pietro Nasseti. São Paulo: Martin Claret, 2003.

BIZZARRI, Hugo Oscar. Castigos del rey don Sancho IV. Ed. Introd. Y notas de. Madrid: Editorial Iberoamericana de Libros Ediciones. 2001.

GAYANGOS, P.(Ed.). Castigos e documentos del rey don Sancho IV. In Escritores en prosa anteriores al siglo XV. Madrid: Atlas, 1952. p. 79-228 (Biblioteca de Autores Españoles, 51)

\section{REFERÊNCIAS BIBLIOGRÁFICAS}

CACHO BLECUA, J.M. El título de los Castigos y documentos de Sancho IV. In La literatura en la época de Sancho IV. Actas del congreso Internacional La Literatura en la época de Sancho IV. Alcalá de Henares, 21-24 de febrero de 1994, eds., Carlos Alvar e José Manuel Lucia Megías, Alcalá de Henares, Universidad de Alcalá 1996, p. 153-168.

FOULCHÉ-DELBOSC, R. Les Castigos e documentos de Sanche IV. In Review hispanique, 15, 1906, p 340371.

IGLESIA DUARTE, J,I. (coord.) Memoria, Mito y Realidad en la Historia. XIII Semana de Estudios Medievales Nájera 2002. Logroño: Gobierno de la Rioja- IER Instituto de Estudios Riojanos, 2003.

REY, A. (Ed) Castigos e documentos para bien vivirordenado por el rey don Sancho IV. Bloomington: Indiana Uiversity Press, 1952.

RIBEIRO, D.V. Igreja e Estado na Idade Média. Relações de Poder. Belo Horizonte: Ed. Lê, 1995.

SESMA MUÑOZ, J. A. La creación de la memória histórica, uma selección interesada del pasado. In : IGLESIA DUARTE, J,I. (coord.) Memoria, Mito y Realidad en la Historia. XIII Semana de Estudios Medievales Nájera 2002. Logroño: Gobierno de la Rioja- IER Instituto de Estudios Riojanos, 2003. p. 1332. 